\title{
Important Factors Affecting Adjuvant Treatment Decision in Stage IA Breast Cancer Patients in Turkey
}

\author{
Bala B. Oven Ustaalioglu ${ }^{a}$ Ahmet Bilicib Burçak E. Yilmaz ${ }^{a}$ \\ Mehmet Aliustaoglua Mesut Seker $^{c} \quad$ Fugen Vardar ${ }^{d} \quad$ Mahmut Gumus $^{c}$ \\ aDepartment of Medical Oncology, Haydarpasa Numune Education and Research Hospital, \\ ${ }^{b}$ Department of Medical Oncology, Medipol University, \\ 'Department of Medical Oncology, Kartal Education and Research Hospital, \\ ${ }^{\mathrm{d} D e p a r t m e n t}$ of Pathology, Haydarpasa Numune Education and Research Hospital, Istanbul, Turkey
}

\section{Keywords}

Breast cancer - Stage IA - Adjuvant therapy .

Chemotherapy

\section{Summary}

Introduction: In Turkey, the gene expression profile test is not standard, so adjuvant treatment is planned according to clinicopathological factors. Therefore, we retrospectively analyzed important parameters that affect the decision on adjuvant chemotherapy, and also factors related to survival in stage IA breast cancer patients in Turkey. Methods: We retrospectively evaluated 347 stage IA patients. The relationship between the clinicopathological parameters and adjuvant chemotherapy was analyzed. Results: The median age and follow-up time were 52 years (range: 25-86) and 22.6 months (range: 1-113), respectively. The 5-year disease-free survival (DFS) and overall survival (OS) rates were $87.9 \%$ and $98.7 \%$, respectively, but the median DFS was not reached. Age, estrogen receptor (ER) status, human epidermal growth factor receptor 2 (HER2) status, and the presence of triple-negative breast tumor (TNBC) were related to DFS, and lymphovascular invasion (LVI), perineural invasion (PNI), HER2 status, the presence of TNBC, and recurrence were related to OS ( $<<0.05)$. Furthermore, age, menopausal status, multicentricity, grade, tumor size, necrosis, ER, the presence of TNBC, and HER2 were found to be related to adjuvant therapy decision $(p<0.05)$. All these parameters, in addition to LVI and PNI, were independent factors for chemotherapy by logistic regression analysis. Conclusions: In decisions about adjuvant therapy in stage IA breast cancer patients, clinicopathological factors should be kept in mind.

\section{Introduction}

Breast cancer is the most common cancer and is the leading cause of cancer-related death for women [1]. Surgery is possible for most patients, after which they can receive adjuvant chemotherapy, radiotherapy, or hormonotherapy to reduce the risk of relapse [2]. Tumor size, hormone receptor status, human epidermal growth factor receptor 2 (HER2) overexpression, histological grade, and axillary lymph node (ALN) involvement have been established to be important prognostic factors for recurrence [2,3]. Despite the availability of new prognostic or predictive factors and gene expression profiling, clinicopathological factors are still considered important for therapy decisions [4]. Chemotherapy has marginal benefit for lymph node-negative early breast cancer, because of the relatively low risk of recurrence [5]. Chemotherapy is offered to patients that have high-risk features such as high grade, large tumor size $(>2 \mathrm{~cm})$, pathologically involved ALN, and/or high 21-gene recurrence score (>31) [6].

T1N0 tumors are considered to have good prognosis and the need for adjuvant chemotherapy is controversial [7]. Genomic signatures could identify patients who do not need chemotherapy, so that undesirable side effects can be prevented [8], but in Turkey, genomic tests cannot be used in routine practice because of the high cost. The aim of the present study was to analyze the factors affecting the decision on adjuvant treatment in our stage IA breast cancer patients.

\section{Material and Methods}

The data of the 1,324 breast cancer patients who were treated at 3 different medical oncology departments in Istanbul between May 2005 and March 2012 were included. All patients underwent modified radical mastectomy (MRM) or breast-conserving surgery (BCS). We analyzed 347 patients who had a breast tumor of $\leq 2 \mathrm{~cm}$ without ALN metastasis. Patients who received neoadjuvant chemotherapy or had distant metastasis

\section{KARGER \\ Fax +497614520714 \\ Information@Karger.com}

www.karger.com (c) 2014 S. Karger GmbH, Freiburg

661-3791/14/0092-0123\$39.50/0

Accessible online at:

www.karger.com/brc
Bala Bașak Oven Ustaalioglu, M.D.

Department of Medical Oncology

Haydarpasa Numune Education and Research Hospital

Selimiye Mah, Șair Nesimi sok, Kardeșler Apt.

No. 1, Daire 4, 34668 Uskudar, Istanbul, Turkey

basakoven@yahoo.com 
or secondary malignancies were excluded. This study was a retrospective and review-based study of medical records of patients at our institutions. Clinical information and pathological parameters such as lymphovascular invasion (LVI), perineural invasion (PNI), hormone receptor (HR) status, and HER2 expression were obtained from patients' charts.

Table 1. Characteristics of the tumors

\begin{tabular}{|c|c|c|}
\hline Characteristics & $\mathrm{n}$ & $\%$ \\
\hline \multicolumn{3}{|l|}{ Tumor location } \\
\hline Right & 168 & 48.4 \\
\hline Left & 174 & 50.1 \\
\hline Bilateral & 5 & 1.4 \\
\hline \multicolumn{3}{|l|}{ Histopathological type } \\
\hline Invasive ductal carcinoma & 302 & 87.3 \\
\hline Invasive lobular carcinoma & 10 & 2.9 \\
\hline Other & 35 & 9.8 \\
\hline \multicolumn{3}{|l|}{ Menopausal status } \\
\hline Premenopause & 143 & 41.2 \\
\hline Postmenopause & 204 & 58.8 \\
\hline \multicolumn{3}{|l|}{ Operation type } \\
\hline MRM & 165 & 47.6 \\
\hline BCS & 179 & 51.6 \\
\hline Simple mastectomy & 3 & 0.9 \\
\hline \multicolumn{3}{|l|}{ Multicentricity } \\
\hline Present & 46 & 13.3 \\
\hline Absent & 301 & 86.7 \\
\hline \multicolumn{3}{|l|}{ Grade } \\
\hline 1 & 92 & 26.5 \\
\hline 2 & 166 & 47.8 \\
\hline 3 & 78 & 22.5 \\
\hline Unknown & 11 & 3.2 \\
\hline \multicolumn{3}{|l|}{ Tumor size } \\
\hline$\leq 1 \mathrm{~cm}$ & 89 & 25.6 \\
\hline$>1 \mathrm{~cm}$ & 258 & 74.4 \\
\hline \multicolumn{3}{|l|}{ Lymphovascular invasion } \\
\hline Present & 61 & 17.6 \\
\hline Absent & 238 & 63.6 \\
\hline Unknown & 48 & 13.8 \\
\hline \multicolumn{3}{|l|}{ Perineural invasion } \\
\hline Present & 47 & 13.5 \\
\hline Absent & 146 & 42.1 \\
\hline Unknown & 154 & 44.4 \\
\hline \multicolumn{3}{|l|}{ Necrosis } \\
\hline Present & 41 & 11.8 \\
\hline Absent & 187 & 53.9 \\
\hline Unknown & 119 & 34.3 \\
\hline \multicolumn{3}{|l|}{ ER } \\
\hline Positive & 258 & 74.4 \\
\hline Negative & 89 & 25.6 \\
\hline \multicolumn{3}{|l|}{ PR } \\
\hline Positive & 257 & 74.3 \\
\hline Negative & 89 & 25.7 \\
\hline \multicolumn{3}{|l|}{ HER2 } \\
\hline Positive & 60 & 17.3 \\
\hline Negative & 271 & 77.2 \\
\hline Unknown & 16 & 5.5 \\
\hline \multicolumn{3}{|l|}{ Triple negative } \\
\hline Present & 29 & 8.4 \\
\hline Absent & 318 & 91.6 \\
\hline \multicolumn{3}{|l|}{ Recurrence } \\
\hline Present & 154 & 44.4 \\
\hline Absent & 193 & 55.6 \\
\hline
\end{tabular}

MRM = Modified radical mastectomy,

$\mathrm{BCS}=$ breast-conserving surgery, $\mathrm{ER}=$ estrogen receptor,

$\mathrm{PR}=$ progesterone receptor.
Patients received adjuvant radiotherapy if they had undergone BCS. In addition, patients received adjuvant hormonotherapy or trastuzumab based on HR status and HER 2 expression, respectively. Risk factors were defined as age $<40$ years, the presence of LVI and PNI, high-grade tumor $(>2)$, negative ER, positive HER2, and tumor size $>1 \mathrm{~cm}$. Patients were categorized according to the number of risk factors, as $1,2,3$, or $\geq 4$.

Table 2. Results of univariate analysis

\begin{tabular}{|c|c|c|c|c|}
\hline \multirow[t]{2}{*}{ Characteristics } & \multicolumn{2}{|c|}{ 5-year DFS } & \multicolumn{2}{|c|}{ 5-year OS } \\
\hline & Rate, \% & $\mathrm{p}$ & Rate, \% & $\mathrm{p}$ \\
\hline Age & & 0.01 & & 0.1 \\
\hline$\leq 40$ years & 74.2 & & 94.4 & \\
\hline$>40$ years & 90.9 & & 99.5 & \\
\hline Tumor location & & 0.1 & & 0.3 \\
\hline Left & 84 & & 97.5 & \\
\hline Bilateral & 90 & & na & \\
\hline Menopausal status & & 0.2 & & 0.9 \\
\hline Premenopause & 77 & & 99 & \\
\hline Postmenopause & 95 & & 98 & \\
\hline Operation type & & 0.2 & & 0.9 \\
\hline MRM & 91 & & 98 & \\
\hline $\mathrm{BCS}$ & 82 & & 99 & \\
\hline Multicentricity & & 0.5 & & 0.5 \\
\hline Present & na & & na & \\
\hline Absent & 86.6 & & 98 & \\
\hline Grade & & 0.3 & & 0.4 \\
\hline 1 & 89.9 & & & \\
\hline 2 & 85.4 & & & \\
\hline 3 & 93 & & & \\
\hline Unknown & 75 & & na & \\
\hline Tumor diameter & & 0.3 & & 0.4 \\
\hline$\leq 1 \mathrm{~cm}$ & 80.9 & & na & \\
\hline$>1 \mathrm{~cm}$ & 90.6 & & 98 & \\
\hline Lymphovascular & & & & \\
\hline invasion & & 0.2 & & 0.03 \\
\hline Present & 84.2 & & 94.5 & \\
\hline Absent & 94.4 & & na & \\
\hline Perineural invasion & & 0.06 & & $<0.001$ \\
\hline Present & 81.5 & & na & \\
\hline Absent & 88.8 & & 99.3 & \\
\hline Necrosis & & 0.06 & & 0.1 \\
\hline Present & 92.9 & & 96.7 & \\
\hline Absent & 92.9 & & na & \\
\hline ER & & 0.006 & & 0.7 \\
\hline Positive & 93 & & 99.5 & \\
\hline Negative & 72 & & 96.3 & \\
\hline PR & & 0.1 & & 0.7 \\
\hline Positive & 89.7 & & 99.5 & \\
\hline Negative & 81.8 & & 96 & \\
\hline HER2 & & 0.001 & & 0.03 \\
\hline Positive & 82.5 & & na & \\
\hline Negative & 88.2 & & 98 & \\
\hline Adjuvant CT & & 0.1 & & 0.1 \\
\hline Present & 86.5 & & 97.2 & \\
\hline Absent & 89 & & na & \\
\hline Triple negative & & 0.05 & & 0.01 \\
\hline Present & 78.4 & & 83.3 & \\
\hline Absent & 89 & & 99.6 & \\
\hline Recurrence & & & & $<0.001$ \\
\hline Present & & & 87 & \\
\hline Absent & & & na & \\
\hline Risk factors & & 0.3 & & 0.003 \\
\hline
\end{tabular}




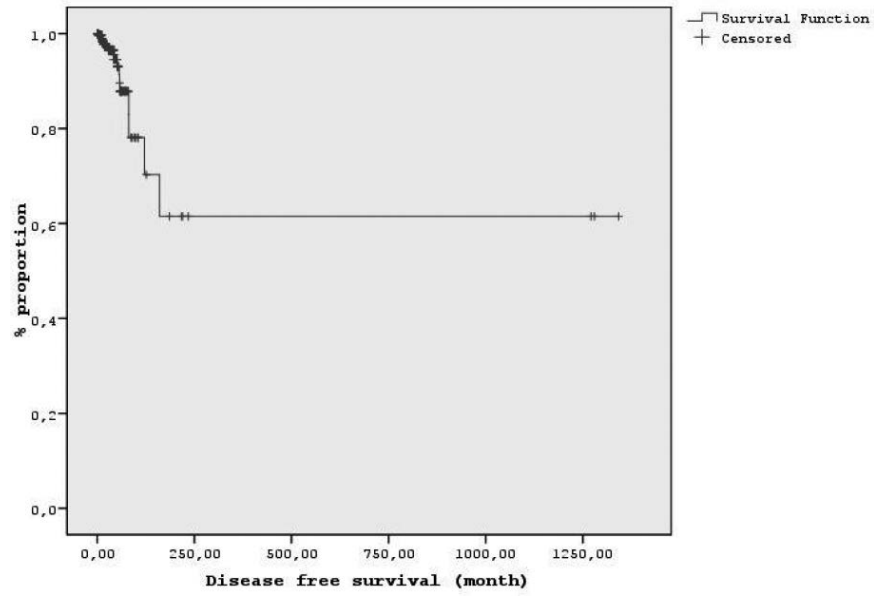

Fig. 1. Disease-free survival curve.

\section{Statistical Analysis}

Statistical analyses were performed using SPSS 17.0 (SPSS Inc., Chicago, IL, USA) software. Chi-square and logistic regression analyses were performed to detect the relationship between the clinicopathological parameters and adjuvant therapy. Disease-free survival (DFS) was defined as the time from surgery to the last follow-up and the time until recurrence. In addition, overall survival (OS) was described as the time from diagnosis to the date of the patient's death or last known contact. Survival analysis and curves were established according to the KaplanMeier method and compared using the log-rank test. Prognostic factors analyzed by univariate analysis were also evaluated with multivariate analysis using the Cox proportional hazards model. The $95 \%$ confidence interval $(\mathrm{CI})$ was used to quantify the relationship between survival time and each independent factor. All $\mathrm{p}$ values were 2-sided in tests, and $\mathrm{p}$ values less than or equal to 0.05 were considered to be significant.

\section{Results}

MRM was performed in 165 patients (47.6\%). Approximately $88 \%$ of tumors were invasive ductal carcinomas, $2.9 \%$ were invasive lobular tumors, and $9.8 \%$ were other types of tumor. Over $44 \%$ of patients received adjuvant chemotherapy ( $\mathrm{n}=154) ; 51.6 \%$ of patients received radiotherapy because of BCS $(n=179)$ and $80.3 \%$ of these patients were also treated with adjuvant hormonotherapy (table 1 ).

The median age was 52 years (range: 25-86). 143 patients ( $40 \%$ ) were premenopausal; the remaining 204 patients $(60 \%)$ were postmenopausal. The median number of dissected ALNs was 10 (range: 1-33). At the median follow-up of 22.6 months (range: 1-113), recurrence was detected in 154 patients $(43.1 \%)$. The 5 -year DFS and OS rates were $87.9 \%$ and $98.7 \%$, respectively, but the median OS and DFS could not be reached (fig. 1). In the univariate analysis, age $(p=0.01)$, ER status ( $\mathrm{p}=0.006)$, HER2 status $(\mathrm{p}=0.001)$, and the presence of triple-negative breast cancer $(\mathrm{TNBC})(\mathrm{p}=0.05)$ were related to DFS; LVI $(p=0.03)$, PNI $(p<0,001)$, HER2 status $(\mathrm{p}=0.03)$, the presence of TNBC $(\mathrm{p}=0.01)$, and recurrence
Table 3. Relationship between chemotherapy and clinicopathological factors

\begin{tabular}{|c|c|c|c|}
\hline \multirow[t]{2}{*}{ Characteristics } & \multicolumn{2}{|c|}{ Adjuvant chemotherapy, n (\%) } & \multirow[t]{2}{*}{$\mathrm{p}$} \\
\hline & Yes & No & \\
\hline Age & & & $<0.001$ \\
\hline$\leq 40$ years & $34(73.9)$ & $12(26.1)$ & \\
\hline$>40$ years & $120(39.8)$ & $181(60.2)$ & \\
\hline Tumor location & & & 0.4 \\
\hline Right & $79(47)$ & $89(53)$ & \\
\hline Left & $72(41.3)$ & $102(58.7)$ & \\
\hline Bilateral & $3(60)$ & $2(40)$ & \\
\hline Menopausal status & & & $<0.001$ \\
\hline Premenopause & $82(58.5)$ & $60(41.5)$ & \\
\hline Postmenopause & $72(35.2)$ & $132(64.8)$ & \\
\hline Operation type & & & 0.2 \\
\hline MRM & $74(44.8)$ & $91(55.2)$ & \\
\hline BCS & $80(44.6)$ & $99(55.4)$ & \\
\hline Simple mastectomy & $0(0)$ & $3(100)$ & \\
\hline Multicentricity & & & 0.004 \\
\hline Present & $30(65.2)$ & $16(34.8)$ & \\
\hline Absent & $124(41.1)$ & 177 (58.9) & \\
\hline Grade & & & $<0.001$ \\
\hline 1 & $27(29.3)$ & $65(70.7)$ & \\
\hline 2 & $71(42.7)$ & $95(57.3)$ & \\
\hline 3 & $51(65.3)$ & $27(34.7)$ & \\
\hline Unknown & $5(45.4)$ & $6(54.6)$ & \\
\hline Tumor diameter & & & 0.002 \\
\hline$\leq 1 \mathrm{~cm}$ & $27(30.3)$ & $62(69.7)$ & \\
\hline$>1 \mathrm{~cm}$ & $127(49.2)$ & $131(50.8)$ & \\
\hline Lymphovascular & & & 0.002 \\
\hline invasion & & & \\
\hline Present & $38(62.2)$ & $23(37.8)$ & \\
\hline Absent & $91(38.2)$ & $147(61.8)$ & \\
\hline Unknown & $25(52)$ & $23(48)$ & \\
\hline Perineural invasion & & & 0.1 \\
\hline Present & $27(57.4)$ & $20(42.6)$ & \\
\hline Absent & $66(45.2)$ & $80(54.8)$ & \\
\hline Unknown & $54(39.4)$ & $83(60.6)$ & \\
\hline Necrosis & & & 0.007 \\
\hline Present & $27(65.8)$ & $14(34.2)$ & \\
\hline Absent & $73(39)$ & $114(61)$ & \\
\hline Unknown & $54(45.3)$ & $65(54.7)$ & \\
\hline ER & & & $<0.001$ \\
\hline Positive & $89(34.9)$ & $166(65.1)$ & \\
\hline Negative & 64 (71.9) & $25(28.1)$ & \\
\hline Unknown & $1(33.3)$ & $2(66.7)$ & \\
\hline PR & & & 0.001 \\
\hline Positive & $98(38.4)$ & 157 (61.6) & \\
\hline Negative & $55(59.7)$ & $37(40.3)$ & \\
\hline Unknown & $1(50)$ & $1(50)$ & \\
\hline HER2 & & & $<0.001$ \\
\hline Positive & $45(75)$ & $15(25)$ & \\
\hline Negative & $100(36.7)$ & $172(63.3)$ & \\
\hline Unknown & $9(60)$ & $6(40)$ & \\
\hline Triple negative & & & $<0.001$ \\
\hline Present & $25(86.2)$ & $4(13.8)$ & \\
\hline Absent & $129(40.5)$ & $189(59.5)$ & \\
\hline Recurrence & & & 0.1 \\
\hline Present & $11(61.1)$ & $7(58.9)$ & \\
\hline Absent & $143(43.4)$ & $186(56.6)$ & \\
\hline Risk factors & & & $<0.001$ \\
\hline 0 & $35(25.5)$ & $102(74.5)$ & \\
\hline 1 & $46(54.1)$ & $39(45.9)$ & \\
\hline 2 & $32(68)$ & $15(32)$ & \\
\hline 3 & $17(85)$ & $3(15)$ & \\
\hline$\geq 4$ & $1(3.3)$ & 29 (96.6) & \\
\hline
\end{tabular}

( $\mathrm{p}<0,001)$ were found to be important factors in predicting OS (table 2). Patients with tumors displaying LVI, PNI, and TNBC had worse survival than those with tumors without these characteristics. Patients who had more than 2 risk factors also had worse survival than those patients without risk 
Table 4. Adjuvant chemotherapy related independent factors

\begin{tabular}{lrrrl}
\hline Characteristics & Wald & \multicolumn{1}{c}{$\mathrm{p}$} & $\mathrm{Hr}$ & $95 \% \mathrm{CI}$ \\
\hline Menopausal status & 9.4 & 0.002 & 2.5 & $1.4-4.7$ \\
Multicentricity & 7.1 & 0.007 & 3.1 & $1.3-7.2$ \\
Tumor size & 11.3 & 0.001 & 0.3 & $0.1-0.6$ \\
Grade & 13.8 & $<0.001$ & 0.4 & $0.3-0.6$ \\
LVI & 6.2 & 0.01 & 3.4 & $1.3-9.2$ \\
PNI & 4.3 & 0.03 & 0.3 & $0.1-0.9$ \\
ER status & 10.8 & 0.001 & 0.3 & $0.1-0.6$ \\
HER2 status & 7.5 & 0.006 & 1.9 & $1.2-3$ \\
Presence of TNBC & 6.7 & 0.009 & 10.1 & $1.7-58.6$ \\
\hline
\end{tabular}

$\mathrm{Hr}=$ Hazard ratio, $\mathrm{CI}=$ confidence interval,

LVI = lyphovasculer invasion, $\mathrm{PNI}=$ perineural invasion,

TNBC $=$ triple-negative breast cancer.

factors $(\mathrm{p}=0.03)$. Furthermore, patients older than 40 years, patients with ER-positive, or those with HER2-negative tumor had better DFS than other groups; 5-year DFS rates were $90.9,93$, and $88.2 \%$, respectively. When we carried out multivariate analysis to determine the independent prognostic factors for OS and DFS, we could not find any factor predicting OS, but age and PNI were significantly associated with DFS. 18 tumors $(5.2 \%)$ was classified as T1a $(>1 \mathrm{~mm}$ to $\leq 5 \mathrm{~mm}), 72(20.7 \%)$ as $\mathrm{T} 1 \mathrm{~b}(>5 \mathrm{~mm}$ to $\leq 1 \mathrm{~cm})$, and 127 $(74.1 \%)$ as T1c ( $>1 \mathrm{~cm}$ to $\leq 2 \mathrm{~cm})$, but OS and DFS were not different between these groups $(\mathrm{p}=0.7$ and $\mathrm{p}=0.2$, respectively). Adjuvant chemotherapy was given more frequently for T1c $(n=127)$ compared with T1b $(n=21)$ or T1a $(n=6)$ $(\mathrm{p}=0.006)$.

Chemotherapy was given to $34.9 \%$ of the ER-positive, $75 \%$ of the HER2-positive, and $86.2 \%$ of the TNBC subgroups. Adjuvant chemotherapy was anthracycline based $(86.2 \%)$ or composed of a combination of anthracycline and taxane $(13.8 \%) .6$ patients with a tumor positive for HER2 and $\leq 1 \mathrm{~cm}$ in size received trastuzumab, followed by anthracycline-based chemotherapy; 49 patients with HER2-positive tumors received a combination of anthracycline and taxane, followed by trastuzumab therapy in adjuvant settings. Patients who received adjuvant chemotherapy were more frequently premenopausal: 82 premenopausal (58.5\%) and 72 postmenopausal $(35.2 \%)(\mathrm{p}<0.001)$. Receipt of hormonotherapy did not differ between pre- or postmenopausal patients (79.5 vs. $85.3 \%$, respectively, $\mathrm{p}=0.1)$. Furthermore, age $(\mathrm{p}<0.001)$, multicentricity $(p=0.004)$, grade $(p<0.001)$, tumor size $(\mathrm{p}<0.002)$, necrosis $(\mathrm{p}=0.007)$, ER $(\mathrm{p}<0.001)$, progesterone receptor $(P R)$ status $(p=0.001)$, HER2 status $(p<0.001)$, the presence of TNBC $(\mathrm{p}<0.001)$, and the number of risk factors $(\mathrm{p}<0.001)$ were found to be related to receiving adjuvant therapy. Patients younger than 40 years and premenopausal patients had received more adjuvant chemotherapy compared with patients older than 40 years and postmenopausal patients. Moreover, patients with multicentric tumors, tumors showing high grade, $>1$-cm diameter, LVI, PNI, or necrosis, and tumors that were negative for ER, negative for PR, positive for HER2, or TNBC were more frequently treated with adjuvant chemotherapy than those with tumors without these features (table 3). Menopausal status, multicentricity, tumor diameter, grade, the presence of LVI and PNI, ER and HER2 status, and the presence of TNBC were confirmed as independent parameters for the decision on adjuvant chemotherapy. Table 4 shows the results of the logistic regression analysis.

\section{Discussion}

Many patients receive adjuvant chemotherapy with little benefit but with substantial toxicities for early-stage breast cancer. Therefore, it is important to determine the prognostic factors that could help to select patients who would most likely benefit from systemic chemotherapy. The criteria for adjuvant treatment in lymph node-negative and $<2 \mathrm{~cm}$ breast cancer have become confusing [9]. Tumors of $\leq 5 \mathrm{~mm}$ without ALN metastasis that are ER/PR-positive and HER2-negative do not require chemotherapy, but there is no consensus for tumors of $>5 \mathrm{~mm}$ with the same characteristics. Adjuvant chemotherapy has been recommended for HR-negative tumors [9] and HER2-positive tumors of $>1 \mathrm{~cm} \mathrm{[4].} \mathrm{In} \mathrm{the} \mathrm{pre-}$ sent study, we evaluated the parameters related to treatment decisions in small lymph node-negative breast cancer in our population.

In retrospective studies, the 10-year relapse-free survival (RFS) rate of ALN-negative tumors of $\leq 1 \mathrm{~cm}$ was reported to be $>90 \%$ without adjuvant therapy [10]. Sánchez-Muñoz et al. [7] reported that over half of the 238 breast cancer patients with tumors of $<1 \mathrm{~cm}$ did not receive therapy, $43 \%$ received hormonotherapy, $4 \%$ received chemotherapy, and $2 \%$ received both modalities in adjuvant settings. There were no factors related to DFS, and the prognosis of patients was excellent in spite of the absence of adjuvant chemotherapy. In our study, we evaluated all 347 stage IA patients, not only those with tumors of $<1 \mathrm{~cm}$. Adjuvant chemotherapy was given to $154(44.4 \%)$ patients, and adjuvant hormonotherapy was given to 288 of our patients with or without chemotherapy. Joensuu et al. [11] reported that, in the Finnish population of 852 stage IA breast cancer patients, $5 \%$ received adjuvant chemotherapy. HER2 status, grade, and tumor diameters were found to be significant prognostic factors. In the univariate analysis, we found that age, ER status, HER2 status, and the presence of TNBC were related to DFS. On the other hand, LVI, PNI, HER2 status, the presence of TNBC, and recurrence were found to be important factors in predicting OS, which is similar to that found in the literature. We also categorized risk factors, and patients who had more than 2 risk factors had worse survival than those with 1 risk or no risk factors. While we could not find any factor predictive for OS, age and PNI were significantly associated with DFS by multivariate analysis. Gonzalez-Angula et al. [12] reported a higher 
risk of recurrence in HER2-positive or triple-negative stage IA breast cancer without adjuvant chemotherapy. We also found that HER2-positive TNBC and ER-negative tumors had worse DFS than HR-positive or HER2-negative tumors, which is consistent with the literature. In our study, patients older than 40 years also had better survival than those of 40 years or younger, similar to the findings of Theriault et al. [13]. However, they used a cut-off value for age of 35 years.

An excellent outcome was reported for 194 lymph nodenegative, triple-negative tumors of $\leq 1 \mathrm{~cm}, 58 \%$ of whom were treated with chemotherapy [14]. Chemotherapy was given more frequently to patients with high-grade tumors, of a younger age, or with tumors of $>0.5 \mathrm{~cm}$, as in our study. We also found a preference for chemotherapy to be given to premenopausal patients and those with multicentric tumors with LVI and necrosis, as well as in adjuvant settings for patients with 2 or more risk factors. Although the presence of multicentricity or necrosis has not been used as a standard factor in decisions about adjuvant chemotherapy, these 2 parameters were found to affect adjuvant treatment decisions, but were not found to be statistically significant for either OS or DFS.

In a French study, 33 of the 75 patients with ALN-negative, HER2-positive tumors of $<1 \mathrm{~cm}$ received adjuvant chemotherapy. Adjuvant chemotherapy was more frequently chosen for HR-negative and poorly differentiated tumors [15]. In our study, 60 tumors $(17.3 \%)$ were HER2-positive. Two-thirds of HER2-positive tumors received adjuvant chemotherapy with or without trastuzumab. The median tumor size of the patients who did not received chemotherapy was $1 \mathrm{~cm}$ $(0.4-2 \mathrm{~cm})$, despite HER2 positivity. In addition, 11 of the 60 HER2-positive patients who had tumors of $\leq 1 \mathrm{~cm}$ received adjuvant chemotherapy (6 with trastuzumab).
Gene expression profiling is increasingly used to assess prognosis and response to treatment [15]. The 21-gene recurrence score can be used to predict the risk of recurrence in patients with ALN-negative and HR-positive early breast cancer. Although the Oncotype DX or Mammaprint test can be recommended for aiding the decision on whether to use adjuvant chemotherapy, these tests were validated in specific patient populations; for the group with an intermediate risk of recurrence, the risk score is ambiguous for predicting the benefit of chemotherapy [16]. In Turkey, the recurrence score test is not routinely used in outpatient clinics because of the absence of reimbursement from social insurance. Therefore, we have to make adjuvant treatment decisions based on the patient's and the tumor's characteristics.

The prognosis of ALN-negative small breast cancer depends on several clinicopathological factors. Adjuvant treatment decisions should be weighted, including the benefits, side effect and the cost of treatment. Because gene expression profiling is not reimbursed by the government, less than $1 \%$ of our patients can accept this test. Thus, we prefer pathological factors that are reported routinely in pathology results. We believe that our results contribute to the literature because they point out the important factors in the decisionmaking on adjuvant therapy for small ALN-negative breast cancer in our population.

\section{Disclosure Statement}

The authors declare that there are no conflicts of interest. This manuscript was not supported by any financial assistance or other relationships.

\section{References}

1 Chu KC, Tarone RE, Kessler LG, et al.: Recent trends in U.S. breast cancer incidence, survival, and mortality rates. J Natl Cancer Inst 1996;88:15711579.

2 Megale Costa LJ, Soares HP, Gaspar HA, et al.: Ratio between positive lymph nodes and total dissected axillaries lymph nodes as an independent prognostic factor for disease-free survival in patients with breast cancer. Am J Clin Oncol. 2004; 27:304-306.

3 Voordeckers M, Vinh-Hung V, Van de Steene J, et al.: The lymph node ratio as prognostic factor in node-positive breast cancer. Radiother Oncol 2004;70:225-230.

4 Gamucci T, Vaccaro A, Ciancola F, et al.: Recurrence risk in small, node-negative, early breast cancer: A multicenter retrospective analysis. J Cancer Res Clin Oncol 2013;139:853-860.

$\checkmark 5$ Early Breast Cancer Trialists' Collaborative Group (EBCTCG): Effects of chemotherapy and hormonal therapy for early breast cancer on recurrence and 15-year survival: An overview of the randomised trials. Lancet 2005;365:16871717.
6 Brewster AM, Hortobagyi GN, Broglio KR, et al.: Residual risk of breast cancer recurrence 5 years after adjuvant therapy. J Natl Cancer Inst 2008; 100:1179-1183.

7 Sánchez-Muñoz A, Pérez-Ruiz E, Jurado JM, et al.: Outcome of small invasive breast cancer with no axillary lymph node involvement. Breast J 2011; 17:32-38.

8 Sotiriou C, Piccart MJ: Taking gene-expression profiling to the clinic: When will molecular signatures become relevant to patient care? Nat Rev Cancer 2007;7:545-553.

9 Schwartz GF, Reis-Fihlo J, Pusztai L, et al.: Adjuvant therapy in stage I carcinoma of the breast: the influence of multigene analyses and molecular phenotyping. Cancer 2012 15;118:2031-2038.

10 Banerjee S, Smith IE: Management of small HER2-positive breast cancers. Lancet Oncol 2010; 11:1193-1199.

11 Joensuu H, Isola J, Lundin M, et al.: Amplification of erbB2 and erbB2 expression are superior to estrogen receptor status as risk factors for distant recurrence in pT1N0M0 breast cancer: A nationwide population-based study. Clin Cancer Res 2003;9:923-930.
12 Gonzalez-Angulo AM, Litton JK, Broglio KR, et al.: High risk of recurrence for patients with breast cancer who have human epidermal growth factor receptor 2-positive, node-negative tumors $1 \mathrm{~cm}$ or smaller. J Clin Oncol 2009;27:5700-5706.

13 Theriault RL, Litton JK, Mittendorf EA, et al.: Age and survival estimates in patients who have node-negative T1ab breast cancer by breast cancer subtype. Clin Breast Cancer 2011;11:325-331.

14 Ho AY, Gupta G, King TA, et al.: Favorable prognosis in patients with $\mathrm{T} 1 \mathrm{a} / \mathrm{T} 1 \mathrm{bN} 0$ triple-negative breast cancers treated with multimodality therapy. Cancer 2012;118:4944-4952.

15 Rodrigues MJ, Wassermann J, Albiges-Suvin L, et al.: Treatment of node-negative infra-centimetric $\mathrm{HE}_{2}{ }^{+}$invasive breast carcinoma: A joint AERIO/REMAGUS study. J Clin Oncol 2009; Suppl:Abstr 517.

16 Nagaraj G, Ma CX: Adjuvant chemotherapy decisions in clinical practice for early-stage nodenegative, estrogen receptor-positive, HER2-negative breast cancer: challenges and considerations. J Natl Compr Canc Netw 2013;11:246-250. 